OPEN ACCESS

Edited by:

Flávio Reis,

University of Coimbra, Portugal

Reviewed by:

Aaron T. Irving,

Zhejiang University-University of Edinburgh Institute, China

Citra Fragrantia Theodorea, University of Indonesia, Indonesia

*Correspondence: Xiangkai Li xkli@lzu.edu.cn Xun $\mathrm{Li}$ Ixdr21@126.com Weilin Jin weilinjin@yahoo.com

tThese authors have contributed equally to this work

Specialty section:

This article was submitted to Infectious Diseases - Surveillance,

Prevention and Treatment a section of the journal

Frontiers in Medicine

Received: 24 November 2021 Accepted: 08 February 2022 Published: 03 March 2022

Citation:

Zhao S, Feng P, Meng W, Jin W, LiX and Li X (2022) Modulated Gut Microbiota for Potential COVID-19

Prevention and Treatment.

Front. Med. 9:811176.

doi: 10.3389/fmed.2022.811176

\section{Modulated Gut Microbiota for Potential COVID-19 Prevention and Treatment}

\author{
Shuai Zhao ${ }^{1 \dagger}$, Pengya Feng ${ }^{1 \dagger}$, Wenbo Meng ${ }^{2}$, Weilin $\mathrm{Jin}^{2 \star}$, Xun $\mathrm{Li}^{2 \star}$ and Xiangkai $\mathrm{Li}^{1 *}$ \\ ${ }^{1}$ Intersection Laboratory of Life Medicine, School of Life Sciences, Lanzhou University, Lanzhou, China, ${ }^{2}$ Medical Frontier \\ Innovation Research Center, Institute of Cancer Neuroscience, The First Hospital of Lanzhou University, The First Clinical \\ Medical College of Lanzhou University, Lanzhou, China
}

COVID-19, caused by severe acute respiratory syndrome coronavirus 2 (SARS-CoV-2) has gained global attention. SARS-CoV-2 identifies and invades human cells via angiotensin-converting enzyme 2 receptors, which is highly expressed both in lung tissues and intestinal epithelial cells. The existence of the gut-lung axis in disease could be profoundly important for both disease etiology and treatment. Furthermore, several studies reported that infected patients suffer from gastrointestinal symptoms. The gut microbiota has a noteworthy effect on the intestinal barrier and affects many aspects of human health, including immunity, metabolism, and the prevention of several diseases. This review highlights the function of the gut microbiota in the host's immune response, providing a novel potential strategy through the use of probiotics, gut microbiota metabolites, and dietary products to enhance the gut microbiota as a target for COVID-19 prevention and treatment.

\section{Keywords: SARS-CoV-2, COVID-19, gut microbiota, immune system, probiotic}

\section{INTRODUCTION}

Emerging respiratory infectious diseases are among the top concerns and fascinations of both the public and scientific/medical communities (1). Since December 2019, coronavirus disease 2019 (COVID-19) has become an international public health emergency caused by severe acute respiratory syndrome coronavirus 2 (SARS-CoV-2). The clinical symptoms of the diseases are fever, cough, and myalgia/fatigue, which can develop into acute respiratory distress syndrome (ARDS), and resulting in death (2). Gastrointestinal symptoms, such as diarrhea, have also been reported in several infectious patients (3).

Respiratory viral infections, such as influenza, are often accompanied by intestinal symptoms, mainly including shifts in the intestinal microbiota composition $(4,5)$. The gut microbiota provides the human host with various biological functions, including metabolizing nutrients, maintaining the normal function of the intestinal mucosal barrier, and promoting immune system development (6). For instance, the gut microbiota can generate anti-inflammatory metabolites including shortchain fatty acids (SCFAs), tryptophan, and niacin (7), promoting CD4 immune cells/Th17 cell proliferation and differentiation (8); and enhance the host's antiviral immune response (9). Thus, balance gut microbiota is associated to maintain systemic health that contributes to resistance to SARS-CoV-2 invasion. This review focuses on the etiology and clinical features, especially intestinal symptoms, of COVID-19 and discusses their effects on the intestinal microecology and the applicable mechanisms whereby the gut microbiota regulates immune and inflammatory responses to coronavirus-related diseases of the host. 


\section{SYMPTOMS OF VIRAL INFECTIONS IN COVID-19}

COVID-19 infection shows non-specific incipient symptoms, and the most common clinical manifestations are fever and dry cough (10). Furthermore, gastrointestinal symptoms, such as diarrhea, have been reported as common manifestations in COVID-19-infected patients (11). Coronavirus entry into host cells is mediated by the transmembrane S-glycoprotein that forms homotrimers protruding from the viral surface (12). The S-glycoprotein $S^{B}$ of SARS-CoV-2 recognizes the angiotensinconverting enzyme 2 (ACE2) receptor on the cell surface, fuses with the cell membrane, and enters the target cell for subsequent replication and assembly (13) (Figure 1). ACE2 is expressed not only in lung tissue but also in esophageal and intestinal epithelia (14). ACE2 is a relevant player in the renin-angiotensin system (RAS), counterbalancing the deleterious effects of angiotensin II. Furthermore, intestinal ACE2 functions as a chaperone for the aminoacid transporter B0AT1. It has been suggested that B0AT1/ACE2 complex in the intestinal epithelium regulates gut microbiota (GM) composition and function, with important repercussions on local and systemic immune responses against pathogenic agents, namely viruses. A previous study pointing that ACE2 imbalance is a key player for the poor outcomes in COVID-19 patients with age-related comorbidities (15).

Additionally, the gut microbiota dysbiosis of COVID-19 is associated with infection severity, and patients suffering from diarrhea increasingly need respiratory assistance and intensive care (16). Thus, diarrhea should be considered a symptom of a possible coronavirus infection and examined for an early diagnosis. Patients showing digestive symptoms receive an average of 9-day treatment from symptoms until admission, whereas patients showing respiratory symptoms receive an average of 7.3-day treatment, indicating that patients showing digestive symptoms spend a longer time in the hospital (17). Furthermore, it is widely known that the gut microbiota is usually influenced by diet, age, and even gender, which means the immunity of a host is also the difference. A previous study showed that gut microbiota diversity is decreased in old age and in patients with certain chronic diseases, which constitute two of the primary fatality groups in COVID-19 infections, it can be assumed that the gut microbiota may play a role in COVID-19 pathology and fatality rate (18).

As for intestinal barrier integrity, inborn and adaptive immune cells can activated and secrete proinflammatory cytokines to the circulatory system, resulting in systemic inflammation (19). COVID-19 patients who suffer from diarrhea and have increased serum interleukin (IL)-6 levels show higher calprotectin concentrations (20). Calprotectin a clinical biomarker for inflammatory bowel diseases and has immunoregulatory functions that could play a potential role in monitoring the disease in the diagnosis and especially the followup of COVID-19-related diarrhea (21). In addition, diarrhea may rank second to virus-induced inflammation due to the access of inflammatory cells to the intestinal mucosa, such as neutrophils and lymphocytes, thereby disrupting the gut microbiota (22).

\section{GUT MICROBIOTA CHANGES IN COVID-19 PATIENTS}

Respiratory viral infections often occur with intestinal symptoms. The composition of intestinal microbiota changes in different lung diseases has been reported (23-25). Several studies have reported gut microbiota changes in the feces of patients suffering from COVID-19 $(26,27)$. Alterations in the gut microbiota were first reported using shotgun metagenomic sequencing that analyzed fecal samples from admission to discharge (27). Cases were classified as mild (no radiographic evidence of pneumonia), moderate (presence of pneumonia), serious (respiratory rate $\geq 30 /$ min or oxygen saturation $\leq 93 \%$ while breathing ambient air), or crucial (respiratory failure needing mechanical ventilation, shock, or organ failure needing intensive care). Microbiome results were compared to cases of communityacquired pneumonia and healthy people, characterized by an enrichment of opportunistic pathogens and depletion of beneficial commensals, at the time of hospitalization (27). Another study compared COVID-19 patients, H1N1 patients, and healthy controls to recognize variations in the gut microbiota (26). The same results were also observed in the studies, with significant differences in fecal microbiomes compared to the control groups with characteristics of enriched opportunistic pathogens and depleted beneficial commensals.

Figure 2 shows the main gut microbiota changes after infection. In which the gut microbiota composition shows stratification with disease severity in line with increased concentrations of inflammatory cytokines and blood markers, including C-reactive protein, lactate dehydrogenase, aspartate aminotransferase, and $\gamma$-glutamyl transferase (28). There is an association between the relative abundance of Coprobacillus, Clostridium ramosum, and Clostridium hathewayi and the severity of COVID-19 but an inverse relationship between abundant Faecalibacterium prausnitzii (which possess antiinflammatory effects) and the disease severity. F. prausnitzii is a commensal bacterium identified as anti-inflammatory based on human clinical data (29). F. prausnitzii has anti-inflammatory effects both in vitro and vivo. As one of its mechanisms of inhibition and inflammation, F. prausnitzii secretes bioactive molecules that can block the activation of nuclear factor- $\kappa \mathrm{B}$ and the production of IL- 8 by intestinal epithelial cells (30). In addition, $F$. prausnitzii can stimulate high secretion levels of IL-10 through peripheral blood mononuclear cells, mucosal dendritic cells (DCs), and macrophages. It probably plays a role in intestinal homeostasis by inhibiting the production of proinflammatory cytokines, including interferon- $\gamma$, tumor necrosis factor- $\alpha$, IL- 6 , and IL-12, and enhancing the suppressive activity of forkhead box $\mathrm{P} 3$ regulatory $\mathrm{T}$ cells (Tregs) in the mucosa (31). F. prausnitzii is a known strain with immunomodulatory potential and can contribute to host defense, which was significantly depleted in patients with COVID-19 infected when compared with non-COVID-19 (32). During hospitalization, several particular intestinal microorganisms, Bacteroides thetaiotaomicron, Bacteroides dorei, and Bacteroides massiliensis downregulating ACE2 expression in the patient's gut, 


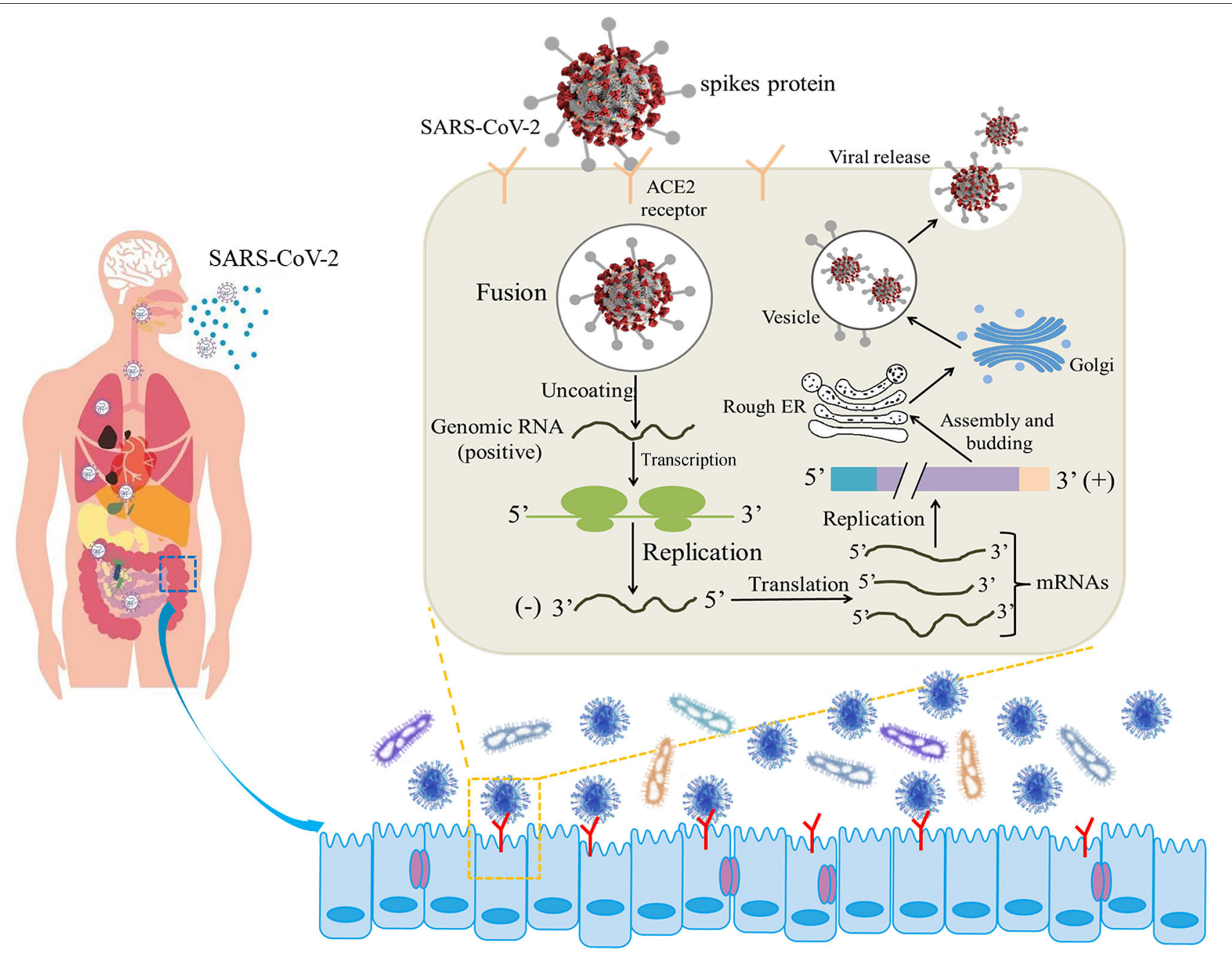

FIGURE 1 | Illustrative model of the entire mechanism of pathogenicity of SARS-CoV-2 (the life cycle of the virus in host cells from attachment to replication) (12, 13).

showed a reverse tendency compared to the load of SARS-CoV2 among fecal samples of the patients. Notably, Coprobacillus strongly upregulated the colonic expression of ACE2 in the murine gut in the previous study (33).

Collectively, these findings suggested that the configuration of the gut microbiome may influence the susceptibility and response to SARS-CoV-2 infection and highlighted a known concept that an original and specific method of modulating the gut microbiota may stand for a therapeutic avenue for COVID-19 and its comorbidities. The persistence of depleted symbionts and gut dysbiosis differed from individuals who considered healthy after clearing SARS-CoV-2, as decided by throat swabs and the resolution of respiratory symptoms. In a recent study, 55 of the 406 cases were tested by anal swab, and results showed that $81.8 \%$ of the stool samples were positive. It is noteworthy that $23.3 \%$ of the stools were still positive after the respiratory viral nucleic acid tested negative, suggesting that the digestive tract clears viruses slower than the respiratory tract (34-36). In the follow-up of patients who recovered from SARS-CoV-2, it has been reported that common clinical sequelae, including general symptoms (49.6\%), respiratory symptoms (39\%), cardiovascularrelated symptoms (13\%), psychosocial symptoms $(22.7 \%)$, and alopecia (28.6\%) (37). Furthermore, some patients retained intestinal microecology dysbiosis after recovery, suggesting that the gut microbiota is closely correlated with the host's immune system during infection and after recovery (28). Therefore, daily intake of beneficial substances, such as probiotics, can improve the gut microbiota composition and enhance the body's immunity, thereby contributing to the prevention and treatment of coronavirus and the alleviation of sequelae (38).

\section{INTESTINAL BARRIER REGULATED BY THE GUT MICROBIOTA FOR COVID-19 PREVENTION}

The interface between a person and their external environment in the body, the intestinal tract has two key functions. 


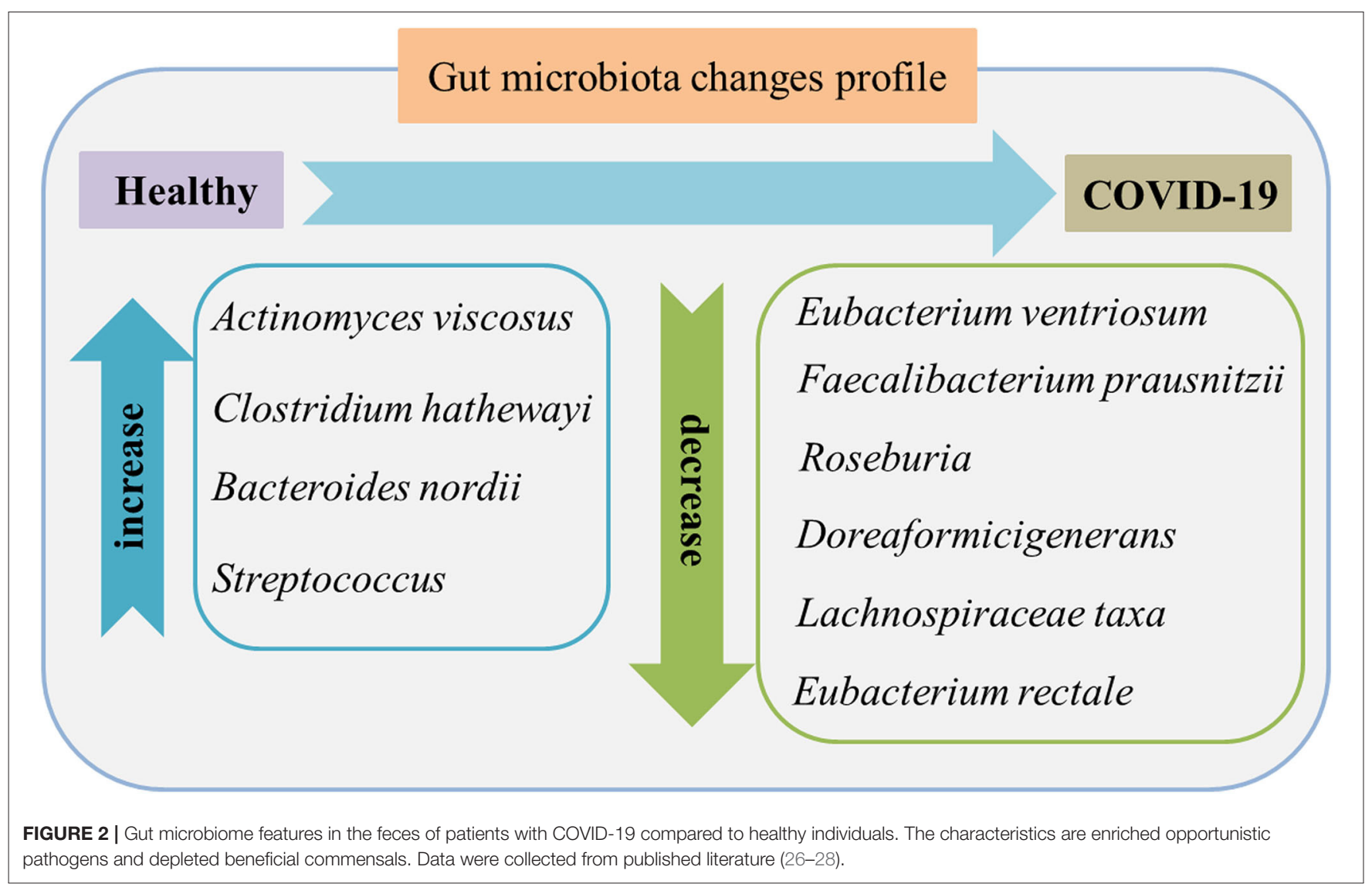

A filter with selected permeability, permits the transfer of required nutrients from the intestinal lumen into circulation and the internal milieu in general. The intestinal tract as a barrier stops the penetration and prevents the movement of some harmful particles, including microorganisms, viruses, and luminal proinflammatory elements (39).

Barrier defenses comprise both immunogenic and nonimmunogenic mechanisms, in which the gut microbiota is the main functional component. Regarding non-immunogenic mechanisms, the primary function is selective intestinal permeability influenced by variations in the gut microbiota. Several commensal bacteria, including Escherichia coli, Klebsiella pneumoniae, and Streptococcus viridans, significantly increase intestinal permeability, allowing harmful entities, such as viruses, to enter circulation more easily, whereas probiotics, such as Lactobacillus brevis, have the counteractive effect, decreasing permeability (40). The intestinal tract is also an active immunological organ with more resident immune cells than anywhere else in the body; the gut microbiota contributes to nonimmunological defenses in the mucosa (41). The homeostasis of the gut microbiota is beneficial to maintain the cooperation between the innate and adaptive immune systems of the host (42). The innate and adaptive immune systems participate in SARS-CoV-2 infections. Lymphopenia with greatly decreased $\mathrm{B}$ and $\mathrm{T}$ cells and programmed cell death-1 is upregulated in severely infected patients (43). Various interventions displayed that the gut microbiota increases antiviral immunity (Table 1). It is supposed that the gut microbiota significantly regulates the growth and function of the innate and adaptive immune systems by influencing immune cells to activate anti-inflammatory responses and keep immune homeostasis, influencing the host's susceptibility to different diseases $(52,53)$. The proinflammatory response should also be considered because the balance between proinflammatory and anti-inflammatory responses is important in many diseases, and understanding how the microbiota shapes immune responses is critical for human health (54). A previous study reported that microbial colonization might provide pro-inflammatory signals that affect the reciprocal development of T-helper and Treg cells. It is suggested that the normal gut microbiota can activate $\mathrm{T}$-cell responses and activate antiviral responses in macrophages by activating inflammasomes and inducing the migration of DCs (9). These findings revealed that the intestinal microbiota acts as a barrier that profoundly impacts the balance between pro-inflammatory and anti-inflammatory immune responses.

The gut microbiota and its metabolites provides protect against thousands of pathogens and closely associates with the host's systemic and pulmonary immune functions (55). SARS-CoV-2 is a reported respiratory pathogen, but intestinal symptoms should also be considered because the intestinal system associates with the immune system. The intestinal and respiratory microbiota develops simultaneously after birth, and 
TABLE 1 | Antiviral functions of the gut microbiota.

\begin{tabular}{|c|c|c|c|}
\hline Bacterial species & Intervention & Mechanisms & References \\
\hline Commensal microbiota & Antibiotic treatment & $\begin{array}{l}\text { Regulates the generation of virus-specific CD } 4 \text { and CD } 8 \text { T cells } \\
\text { Provides signals leading to the expression of mRNA for pro-IL-1 } \beta \text { and } \\
\text { pro-IL-18 }\end{array}$ & $(44)$ \\
\hline Commensal microbiota & Antibiotic treatment & Enhances primary alveolar macrophage function & $(45)$ \\
\hline Commensal microbiota & $\begin{array}{l}\text { Streptococcus pneumoniae } \\
\text { treatment }\end{array}$ & $\begin{array}{l}\text { Modifies neutrophil phenotype through down-regulating neutrophil } \\
\text { expression of an efferocytosis-inhibitory molecule reduces susceptibility to } \\
\text { severe pneumonia }\end{array}$ & $(46)$ \\
\hline $\begin{array}{l}\text { Bacteroides species } \\
\text { increased }\end{array}$ & SCFA treatment & $\begin{array}{l}\text { Enhancement of CD }{ }^{+} \mathrm{T} \text { cell metabolism } \\
\text { Increased generation of macrophages with reduced ability to produce } \\
\text { CXCL1 in airways } \\
\text { Reduced neutrophil recruitment, resulting in the attenuation of lung } \\
\text { immunopathology }\end{array}$ & $(47)$ \\
\hline Clostridium orbiscindens & Antibiotic treatment & Enhanced type I IFN signaling in macrophages & $(48)$ \\
\hline Commensal microbiota & Microbiota transfer & Production of virus-specific CD8 ${ }^{+} \mathrm{T}$ cell responses via dendritic cells & (49) \\
\hline Lachnospiraceae spp. & SCFA treatment & $\begin{array}{l}\text { GPR43-mediated and IFNAR dependent IFN- } \beta \text { responses in lung epithelial } \\
\text { cells }\end{array}$ & $(50)$ \\
\hline $\begin{array}{l}\text { Lactobacillus plantarum } \\
\text { L-137 }\end{array}$ & SCFA treatment & $\begin{array}{l}\text { Proinflammatory activity } \\
\text { Th1 immune response }\end{array}$ & $(51)$ \\
\hline
\end{tabular}

the lungs are inhabited by a microbial population distinct from the gut (56). The interaction between the host and the microbiota shapes different local cell functionalities, immune responses and can further influence disease development (57). Pulmonary immune homeostasis is maintained by a network of tissueresident cells while ensuring that efficient and rapid immune responses can be mounted against invading pathogens (58).

The function of pulmonary immune homeostasis mainly depends on the respiratory mucosa regulated by the microbiota and systemic metabolome (59). Furthermore, a previous study demonstrated a vital cross-talk between the lungs and intestinal mucosal sites of the human body through what is commonly referred to as the "gut-lung axis" (5). The human oral microbe also plays vital roles in the development and maintenance of immune homeostasis (60). Accumulated evidence for the oralgut axis has revealed its role in modulating the pathogenesis process in numerous diseases (61). It is compelling to look into the oral and intestinal microbiome combined with SARS-CoV-2 infection and the crosstalk among them, which may provide an improved understanding of the initiation of viral infection and the path of disease deterioration. The gut microbiota has been shown to influence pulmonary immunity (62). An important player in this gut-immune-lung axis is the microbiota that utilizes dietary components as energy sources, and the resulting metabolic byproducts can be potent immune modulators (63). The movement of immune cells between the gut and lungs can be made through the lymphatic system and/or the blood, thereby modulating the immune response of both organs (64). A number of studies indicated that alterations of early-life microbiota, especially gut microbiota, have consequences for lung diseases. A previous study reported that treatment of mice with vancomycin led to a drop in the diversity of the gut microbiota, which was linked to an exaggerated Th2-driven allergic airway inflammation (65). In recent years, studies have pointed out that it is difficult to distinguish the effects of the intestines, followed by the lungs and the host immune system; in all likelihood, both organs will be significantly important (58). Separating early-life events that influence the gut and the immune system and those that directly influence the lungs is difficult. This relationship is bidirectional, and gut microbiology and physiology could be changed by chronic and acute lung diseases (66). Therefore, in the case of a disrupted intestinal mucosal immune block, invading organisms can access the blood or lungs, leading to ARDS (67). Together, these findings showed that the intestinal tract closely associates with the body's antiviral function, showing promise as a target to resist coronavirus infections.

\section{PROBIOTICS REGULATED GUT MICROBIOTA FOR COVID-19 TREATMENT}

The probiotics function has gained more attention to mediate the gut microbiota exerts an effect on the treatment of environmental contaminants and diseases (68). Probiotics can alter the gut microbiota composition and play essential roles in maintaining the gut microbiota ecosystem (69). Furthermore, several probiotics drive anti-inflammatory and immunoregulatory roles in the settings of enteric infections and mucosal inflammation (70). Although the immune responses caused by bacteria are different from the virus, several previous studies reported that probiotic or gut microbiota is contributed against COVID-19. Probiotics balancing the local microbiota by inhibiting the growth of pathogenic microorganisms (71), and by enhancing local and systemic immune responses (72). They may also influence the composition and activity of microbiota in the intestinal contents. Considering the beneficial effects of probiotics in virus infections, specific probiotics have been suggested to be effective in alleviating the duration and severity of acute rotavirus gastroenteritis (73). 
A previous study demonstrated that the genus Lactobacillus can drive respiratory immune responses to increase the host's defense against respiratory infections (74). Recently, largescale vaccinations have been implemented worldwide to control COVID-19; however, the discovery of mutant viruses may affect vaccine immunity. Furthermore, some studies reported that the gut microbiota could act as immune modulators and natural vaccine adjuvants to affect intestinal immune responses (75). Intestinal dysbiosis play a role in the failure to respond to vaccines (75). In the management of COVID19 Bifidobacterium, promotes efficacy of vaccines against SARSCoV-2 (76). These results provided possible evidence for using probiotics for the defense of COVID-19. However, using probiotics for therapy is worth noting in many aspects. Although probiotics have an excellent overall safety record, they should be used with caution in certain patient groups like neonates born with immunodeficiency. Because of the paucity of information regarding the mechanisms through which probiotics act, appropriate administrative regimens, and probiotic interactions, further investigation is needed in these areas. Finally, note that the properties of different probiotic species vary and can be strain-specific. Therefore, careful consideration should be given to these issues before patients are advised to use probiotic supplements in clinical practice (77).

The intestinal immune system is regulated by microbes and their metabolites. Anaerobic colonic bacteria are adopted to ferment non-digestible carbohydrates, such as cellulose, xylans, resistant starch, and inulin, to yield energy for microbial development (78). The most frequently used probiotics, such as lactic acid bacteria and bifidobacteria, can also generate SCFAs by fermenting carbohydrate end-products (79). The generated SCFAs, such as butyric acid and propionic acid, are the most important metabolites with many microbials, which play a significant role for adjusting the intestinal mucosal immune block and keeping their common functions during respiratory tract infections (63). Moreover, SCFAs can strengthen the number and function of Tregs, thus weakening excessive inflammation and immune response in airway diseases (80). Different dietary carbohydrates not digested by the host, called "prebiotics", can selectively stimulate the development and metabolic activity of probiotic bacteria, such as bifidobacteria and lactobacilli. In fact, through combining probiotics-prebiotics (called symbiotic), predominant bacteria and the generation of SCFAs of fecal microbiota can be shifted in a model system of the human colon (81). The generation of SCFAs by these bacteria is a promising fundamental regulatory factor of epithelial proliferation in the gut (82). Except for SCFAs, a lot of other metabolites of the symbiotic gut microbiota associate with host immunity (83). Retinoic acid maintains intestinal immune homeostasis, as IgA production can be promoted by B and Treg cell growth (84). Tryptophan is an energy source for Lactobacillus that can produce ligands for an aryl hydrocarbon receptor, which maintains the homeostasis of the epithelial block and intraepithelial lymphocytes (85). Niacin has been reported to promote anti-inflammatory properties of colonic macrophages and DCs through GPR109A signaling and enable them to induce Treg cells and IL-10-producing T cells (86). During respiratory tract infections, lipopolysaccharides (LPS) act as part of the intestinal mucosal immune block to keep their common functions (87). In addition, lactate and pyruvate can strengthen the immune response by attracting the dendrite protrusion of small intestinal mononuclear cells (88). LPS are part of the intestinal mucosal immune barrier and maintain normal functions during respiratory tract infections (87). The various probiotics and metabolites for pulmonary infectious disease treatment are summarized in Table 2. This evidence demonstrated that dietary fiber could play a significant function in adjusting the gut microbiota further to regulate the intestinal barrier for virus infection and injury. In pathogenic SARS-CoV-2 infections, a healthy gut microbiota also plays a significant role against lung infection and injury (Figure 3).

\section{CONCLUSION AND FUTURE PROSPECTS}

In conclusion, as the third wave of coronavirus epidemic of the 21st century, after SARS and Middle East respiratory syndrome, the COVID-19 pandemic shows a great global social and

TABLE 2 | The functional of different probiotics, microbial products and dietary products for host immunity enhancement to against pulmonary infectious disease.

\begin{tabular}{|c|c|c|}
\hline Characteristics & Main functions & Reference \\
\hline \multicolumn{3}{|l|}{ Probiotics } \\
\hline $\begin{array}{l}\text { Lactobacillus } \\
\text { gasseri }\end{array}$ & $\begin{array}{l}\text { Enhanced inflammatory signals } \\
\text { Enhanced antiviral immune reaction }\end{array}$ & $(74)$ \\
\hline $\begin{array}{l}\text { Lactobacillus } \\
\text { rhamnosus }\end{array}$ & $\begin{array}{l}\text { Enhanced vaccine immune efficacy } \\
\text { Enhanced antiviral immune reaction }\end{array}$ & (89) \\
\hline Lactobacillus casei & $\begin{array}{l}\text { Enhanced phagocytic and killing } \\
\text { activity of alveolar macrophages } \\
\text { Increased levels of IgA, IFN- } \gamma \text {, } \\
\text { and TNF- } \alpha\end{array}$ & (90) \\
\hline Bifidobacterium & Enhanced vaccine immune efficacy & (25) \\
\hline \multicolumn{3}{|c|}{ Microbial metabolites } \\
\hline $\begin{array}{l}\text { Short-chain fatty } \\
\text { acids (SCFAs) } \\
\text { (Butyrate, } \\
\text { Propionate) }\end{array}$ & $\begin{array}{l}\text { Maintenance of mucosal barrier } \\
\text { Enhanced antiviral immune reaction } \\
\text { Anti-inflammatory effect }\end{array}$ & (63) \\
\hline Retinoic acid & $\begin{array}{l}\text { Increased lgA level Treg } \\
\text { cell development }\end{array}$ & (84) \\
\hline Niacin & $\begin{array}{l}\text { Anti-inflammatory effect Increased } \\
\text { activity of macrophages and } \\
\text { dendritic cells Development of T } \\
\text { regulatory cells and IL-10-producing } \\
\text { T cells }\end{array}$ & (86) \\
\hline LPS & $\begin{array}{l}\text { Enhance the mucosal } \\
\text { immune response provide improved } \\
\text { resistance against infection }\end{array}$ & $(87)$ \\
\hline Desaminotyrosine & Increased IFN-1 & $(48)$ \\
\hline \multicolumn{3}{|l|}{ Dietary products } \\
\hline $\begin{array}{l}\text { Carbohydrate } \\
\text { polymers }\end{array}$ & Increased SCFAs & $(91)$ \\
\hline Prebiotics & Increased SCFAs & (92) \\
\hline
\end{tabular}




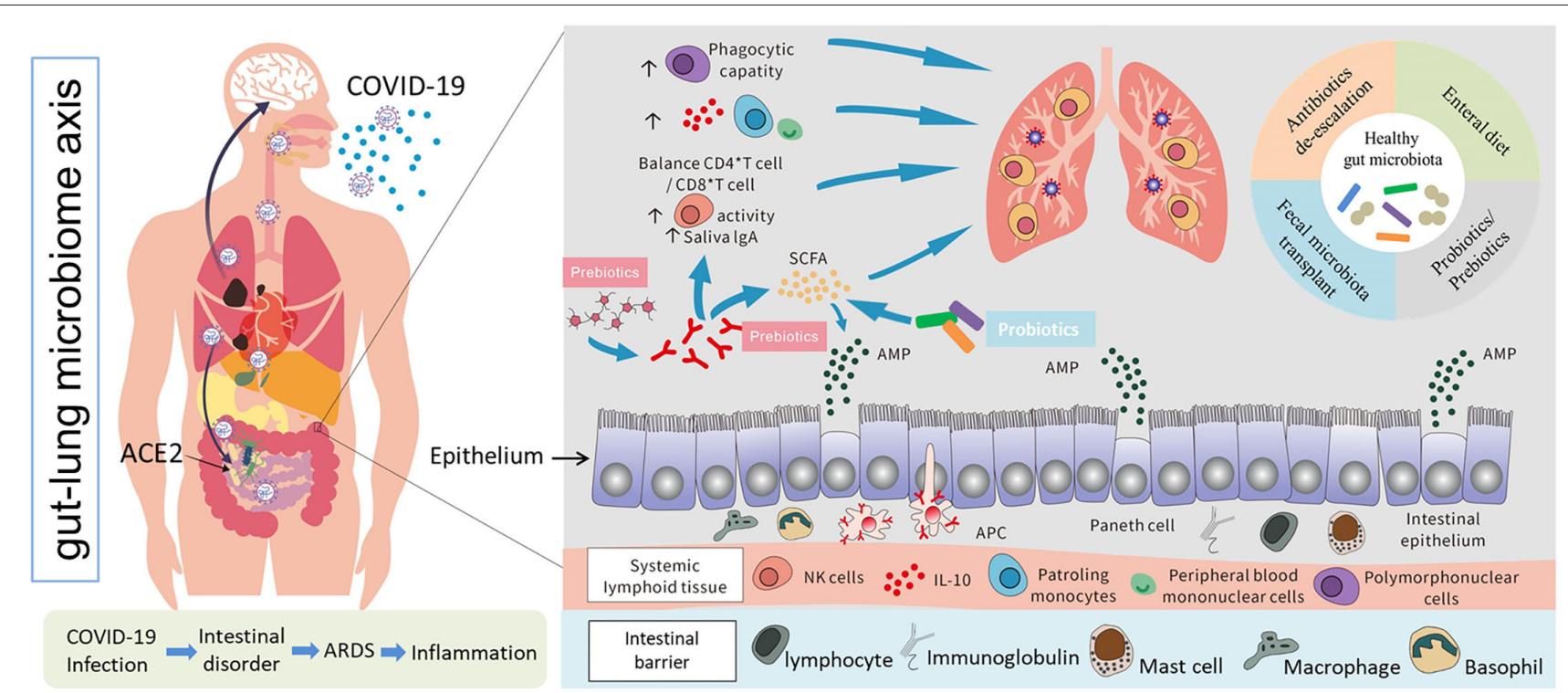

FIGURE 3 | Possible models of SARS-CoV-2 infection, interactions between the human gut and lungs, and potential positive immune responses triggered by probiotics and other prebiotics against lung infection and injury $(69,70,78-80)$.

TABLE 3 | Clinical trials about using probiotics to regulate gut microbiota for COVID-19 treatment and COVID-19 vaccination efficacy.

\begin{tabular}{|c|c|c|c|c|}
\hline Identifier & Country/location & Intervention & Study design & Main aim \\
\hline NCT04366089 & Italy & Probiotic & Parallel assignment & Treatment COVID-19 \\
\hline NCT04366180 & Spain & Probiotic & Parallel assignment & Treatment COVID-19 \\
\hline NCT04399252 & Unit States & Probiotic & Parallel assignment & Treatment COVID-19 \\
\hline NCT04420676 & Austria & Synbiotic & Parallel assignment & Treatment COVID-19 \\
\hline NCT04980560 & $\begin{array}{l}\text { Prince of Wales Hospital, } \\
\text { Hong Kong }\end{array}$ & Probiotic & An observation study & $\begin{array}{l}\text { Compare microbiome profile in } \\
\text { subjects with different COVID-19 } \\
\text { vaccination and subjects recovered } \\
\text { from COVID-19 }\end{array}$ \\
\hline NCT04884776 & $\begin{array}{l}\text { Prince of Wales Hospital, } \\
\text { Hong Kong }\end{array}$ & $\begin{array}{l}\text { 3Bifidobacteria at } 2 \times 1,010 \\
\text { CFU for } 12 \text { weeks }\end{array}$ & Parallel assignment & $\begin{array}{l}\text { Restore gut microbiota to increase } \\
\text { COVID- } 19 \text { vaccine efficacy and } \\
\text { reduce side-effects }\end{array}$ \\
\hline NCT04798677 & $\begin{array}{l}\text { Hospital Mare de Déu de la } \\
\text { Merc, Spain }\end{array}$ & $\begin{array}{l}\text { ABBC1 including } \\
\text { beta-glucans, Inactivated } \\
\text { saccharomyces cerevisae, } \\
\text { Selenium, and Zinc }\end{array}$ & Parallel assignment & $\begin{array}{l}\text { Enhance immune responses including } \\
\text { generation of } \mathrm{T} \text { cells, IgM and lgG }\end{array}$ \\
\hline
\end{tabular}

economic pressure. Given the close association between viral replication and gastrointestinal immunity, a healthy intestinal barrier strategy targeting and modulating the host immune response may effectively decrease viral replication and its spread to the circulatory system. Additionally, probiotic uses have been reported as a promising strategy for severe COVID-19 infection treatment by China's National Health Commission and studies by the National Administration of Traditional Chinese Medicine. Probiotics improve the composition of the gut microbiota and the function of microbial metabolites. Most importantly, coronavirus-targeting vaccines and antiviral drugs have been developed to prevent COVID-19 and future epidemics (Table 3). Notably, according to several results, intestinal dysbiosis may affect the failure to respond to vaccines. With regard to this, the gut microbiota could influence intestinal immune responses as immune modulators and natural vaccine adjuvants. Therefore, the probiotic bacterial polysaccharide structure can be regarded as a lipopeptide-based vaccine. Thus, in the control of COVID19 and other coronavirus-mediated diseases, it is potential for probiotic bacteria to strengthen vaccine efficacy.

\section{AUTHOR CONTRIBUTIONS}

SZ and PF wrote the manuscript. WM revised the manuscript. $\mathrm{XuL}$ and WJ supervised the manuscript. XiL revised and supervised the manuscript. All authors approved the final manuscript. 


\section{FUNDING}

This work was supported by Fundamental Research Funds for the Central Universities, SCUT (No: lzujbky-2020-sp15), Gansu Province Major Science and Technology projects (No:

\section{REFERENCES}

1. Bradley BT, Bryan A. Emerging respiratory infections: the infectious disease pathology of SARS, MERS, pandemic influenza, and Legionella. Semin Diagn Pathol. (2019) 36:152-9. doi: 10.1053/j.semdp.2019.04.006

2. Goyal P, Choi JJ, Pinheiro LC, Schenck EJ, Chen R, Jabri A, et al. Clinical characteristics of Covid-19 in New York City. N Engl J Med. (2020) 382:23724. doi: 10.1056/NEJMc2010419

3. Zhang H, Kang Z, Gong H, Xu D, Wang J, Li Z, et al. The digestive system is a potential route of 2019-nCov infection: a bioinformatics analysis based on single-cell transcriptomes. bioRxiv. (2020). doi: 10.1101/2020.01.30.927806

4. Wang J, Li F, Wei H, Lian ZX, Sun R, Tian Z. Respiratory influenza virus infection induces intestinal immune injury via microbiotamediated Th17 cell-dependent inflammation. J Exp Med. (2014) 211:2397-410. doi: 10.1084/jem.20140625

5. Marsland BJ, Trompette A, Gollwitzer ES. The gut-lung axis in respiratory disease. Ann Am Thorac Soc. (2015) 12 (Suppl. 2):S150-6. doi: 10.1513/AnnalsATS.201503-133AW

6. Belkaid Y, Hand TW. Role of the microbiota in immunity and inflammation. Cell. (2014) 157:121-41. doi: 10.1016/j.cell.2014.03.011

7. Topping DL, Clifton PM. Short-chain fatty acids and human colonic function: roles of resistant starch and nonstarch polysaccharides. Physiol Rev. (2001) 81:1031-64. doi: 10.1152/physrev.2001.81.3.1031

8. Mazmanian SK, Liu CH, Tzianabos AO, Kasper DL. An immunomodulatory molecule of symbiotic bacteria directs maturation of the host immune system. Cell. (2005) 122:107-18. doi: 10.1016/j.cell.2005.05.007

9. Abt MC, Osborne LC, Monticelli LA, Doering TA, Alenghat T, Sonnenberg GF, et al. Commensal bacteria calibrate the activation threshold of innate antiviral immunity. Immunity. (2012) 37:158-70. doi: 10.1016/j.immuni.2012.04.011

10. Zhou F, Yu T, Du R, Fan G, Liu Y, Liu Z, et al. Clinical course and risk factors for mortality of adult inpatients with COVID-19 in Wuhan, China: a retrospective cohort study. Lancet. (2020) 395:105462. doi: 10.1016/S0140-6736(20)30566-3

11. Cheung KS, Hung IFN, Chan PPY, Lung KC, Tso E, Liu R, et al. Gastrointestinal manifestations of SARS-CoV-2 infection and virus load in fecal samples from a Hong Kong cohort: systematic review and meta-analysis. Gastroenterology. (2020) 159:81-95. doi: 10.1053/j.gastro.2020.03.065

12. Tortorici MA, Veesler D. Structural insights into coronavirus entry. Adv Virus Res. (2019) 105:93-116. doi: 10.1016/bs.aivir.2019.08.002

13. Xiao L, Sakagami H. ACE2: the key molecule for understanding the pathophysiology of severe and critical conditions of COVID-19: Demon or Angel? Viruses. (2020) 12:491. doi: 10.3390/v12050491

14. Holshue ML, DeBolt C, Lindquist S, Lofy KH, Wiesman J, Bruce H, et al. First case of 2019 novel coronavirus in the United States. N Engl J Med. (2020) 382:929-36. doi: 10.1056/NEJMoa2001191

15. Viana SD, Nunes S, Reis F. ACE2 imbalance as a key player for the poor outcomes in COVID-19 patients with age-related comorbidities - Role of gut microbiota dysbiosis. Ageing Res Rev. (2020) 62:101123. doi: 10.1016/j.arr.2020.101123

16. Jin X, Lian JS, Hu JH, Gao J, Zheng L, Zhang YM, et al. Epidemiological, clinical and virological characteristics of 74 cases of coronavirus-infected disease 2019 (COVID-19) with gastrointestinal symptoms. Gut. (2020) 69:1002-9. doi: 10.1136/gutjnl-2020-320926

17. Pan L, Mu M, Yang P, Sun Y, Wang R, Yan J, et al. Clinical characteristics of COVID-19 patients with digestive symptoms in Hubei, China: a descriptive, cross-sectional, multicenter study. Am J Gastroenterol. (2020) 115:76673. doi: 10.14309/ajg.0000000000000620
1602FKDA001), Science and Technology Project of Gansu Province (No: 18JR2TA018), Science and Technology Planning Project of Lanzhou Chengguan District (No: 2020JSCX0019) and Gansu Province CoVID-19 (NCP) Science and Technology Major Project (2020) (No: 20YF2FA008).

18. El-Ansary A, Balto H, Al-Hadlaq SM. 3 - Gut-lung cross talk in COVID 19 pathology and fatality rate. In: Kose U, Gupta D, de Albuquerque VHC Khanna A, editors. Data Science for COVID-19. Academic Press (2022). p. $41-59$.

19. Xie C, Jiang L, Huang G, Pu H, Gong B, Lin H, et al. Comparison of different samples for 2019 novel coronavirus detection by nucleic acid amplification tests. Int J Infect Dis. (2020) 93:264-7. doi: 10.1016/j.ijid.2020.02.050

20. Zhang J, Hao Y, Ou W, Ming F, Liang G, Qian Y, et al. Serum interleukin-6 is an indicator for severity in 901 patients with SARS-CoV-2 infection: a cohort study. J Transl Med. (2020) 18:406. doi: 10.1186/s12967-020-02571-x

21. Villapol S. Gastrointestinal symptoms associated with COVID19: impact on the gut microbiome. Transl Res. (2020) 226:5769. doi: 10.1016/j.trsl.2020.08.004

22. Lee C. Porcine epidemic diarrhea virus: an emerging and re-emerging epizootic swine virus. Virol J. (2015) 12:193. doi: 10.1186/s12985-015-0421-2

23. Bruzzese E, Callegari M, Raia V, Viscovo S, Scotto R, Ferrari S, et al. Disrupted intestinal microbiota and intestinal inflammation in children with cystic fibrosis and its restoration with lactobacillus GG: a randomised clinical trial. PLoS ONE. (2014) 9:e87796. doi: 10.1371/journal.pone.0087796

24. Chioma OS, Hesse LE, Chapman A, Drake WP. Role of the microbiome in interstitial lung diseases. Front Med. (2021) 8:595522. doi: 10.3389/fmed.2021.595522

25. Samuelson DR, Welsh DA, Shellito JE. Regulation of lung immunity and host defense by the intestinal microbiota. Front Microbiol. (2015) 6:1085. doi: 10.3389/fmicb.2015.01085

26. Gu S, Chen Y, Wu Z, Chen Y, Gao H, Lv L, et al. Alterations of the gut microbiota in patients with coronavirus disease 2019 or H1N1 influenza. Clin Infect Dis. (2020) 71:2669-78. doi: 10.1093/cid/ciaa709

27. Zuo T, Zhang F, Lui GCY, Yeoh YK, Li AYL, Zhan H, et al. Alterations in gut microbiota of patients with COVID-19 during time of hospitalization. Gastroenterology. (2020) 159:944-55.e8. doi: 10.1053/j.gastro.2020.05.048

28. Yeoh YK, Zuo T, Lui GC-Y, Zhang F, Liu Q, Li AYL, et al. Gut microbiota composition reflects disease severity and dysfunctional immune responses in patients with COVID-19. Gut. (2021) 70:698-706. doi: 10.1136/gutjnl-2020-323020

29. Miquel S, Leclerc M, Martin R, Chain F, Lenoir M, Raguideau S, et al. Identification of metabolic signatures linked to anti-inflammatory effects of Faecalibacterium prausnitzii. MBio. (2015) 6. doi: 10.1128/mBio.00300-15

30. Sokol HD, Seksik P, Rigottier-Gois L, Lay C, Lepage P, Podglajen I, et al. Specificities of the fecal microbiota in inflammatory bowel disease. Inflamm Bowel Dis. (2006) 12:106-11. doi: 10.1097/01.MIB.0000200323.38139.c6

31. Furet JP, Kong LC, Tap J, Poitou C, Basdevant A, Bouillot JL, et al. Differential adaptation of human gut microbiota to bariatric surgery-induced weight loss: links with metabolic and low-grade inflammation markers. Diabetes. (2010) 59:3049-57. doi: 10.2337/db10-0253

32. Liu Q, Mak JWY, Su Q, Yeoh GYK, Lui C-Y, Ng SSS, et al. Gut microbiota dynamics in a prospective cohort of patients with post-acute COVID-19 syndrome. Gut. (2022) 71:544-52. doi: 10.1136/gutjnl-2021-325989

33. Gevazatorsky N, Sefik E, Kua L, Pasman L, Tan TG, Ortizlopez A, et al. Mining the human gut microbiota for immunomodulatory organisms. Cell. (2017) 168:928-43. doi: 10.1016/j.cell.2017.01.022

34. Zhen-Dong Y, Gao-Jun Z, Run-Ming J, Zhi-Sheng L, Zong-Qi D, Xiong $\mathrm{X}$, et al. Clinical and transmission dynamics characteristics of 406 children with coronavirus disease 2019 in China: a review. J Infect. (2020) 81:e115. doi: 10.1016/j.jinf.2020.04.030

35. Ramakrishnan R, Kashour T, Hamid Q, Halwani R, Tleyjeh I. Unraveling the mystery surrounding post-acute sequelae of COVID-19. Front Immunol. (2021) 12:686029. doi: 10.3389/fimmu.2021.686029 
36. Sukocheva OA, Maksoud R, Beeraka NM, Madhunapantula SV, Sinelnikov M, Nikolenko VN, et al. Analysis of post COVID-19 condition and its overlap with myalgic encephalomyelitis/chronic fatigue syndrome. J Adv Res. (2021). doi: 10.1016/j.jare.2021.11.013

37. Xiong Q, Xu M, Li J, Liu Y, Zhang J, Xu Y, et al. Clinical sequelae of COVID-19 survivors in Wuhan, China: a single-centre longitudinal study. Clin Microbiol Infect. (2021) 27:89-95. doi: 10.1016/j.cmi.2020.09.023

38. Infusino $F$, Marazzato $M$, Mancone $M$, Fedele F, Mastroianni C, Severino $\mathrm{P}$, et al. Diet supplementation, probiotics, and nutraceuticals in SARS-CoV-2 infection: a scoping review. Nutrients. (2020) 12:1718. doi: 10.3390/nu12061718

39. Farhadi A, Banan ALI, Fields J, Keshavarzian ALI. Intestinal barrier: an interface between health and disease. J Gastroenterol Hepatol. (2003) 18:4797. doi: 10.1046/j.1440-1746.2003.03032.x

40. García-Lafuente A, Antolín M, Guarner F, Crespo E, Malagelada JR. Modulation of colonic barrier function by the composition of the commensal flora in the rat. Gut. (2001) 48:503. doi: 10.1136/gut.48.4.503

41. Nishio J, Honda K. Immunoregulation by the gut microbiota. Cell Mol Life Sci. (2012) 69:3635-50. doi: 10.1007/s00018-012-0993-6

42. Chassaing B, Aitken JD, Gewirtz AT, Vijay-Kumar M. Gut microbiota drives metabolic disease in immunologically altered mice. Adv Immunol. (2012) 116:93-112. doi: 10.1016/B978-0-12-394300-2.00003-X

43. Diao B, Wang C, Tan Y, Chen X, Liu Y, Ning L, et al. Reduction and functional exhaustion of $\mathrm{T}$ cells in patients with coronavirus disease 2019 (COVID-19). medRxiv. (2020). doi: 10.1101/2020.02.18.20024364

44. Ichinohe T, Pang IK, Kumamoto Y, Peaper DR, Ho JH, Murray TS, et al. Microbiota regulates immune defense against respiratory tract influenza A virus infection. Proc Nat Acad Sci. (2011) 108:5354. doi: 10.1073/pnas.1019378108

45. Schuijt TJ, Lankelma JM, Scicluna BP, Melo FDSE, Roelofs JJTH, De Boer JD, et al. The gut microbiota plays a protective role in the host defence against pneumococcal pneumonia. Gut. (2016) 65:57583. doi: 10.1136/gutjnl-2015-309728

46. Felix KM, Jaimez IA, Nguyen TV, Ma H, Raslan WA, Klinger C, et al. Gut microbiota contributes to resistance against pneumococcal pneumonia in immunodeficient $\mathrm{rag}(-/-)$ mice. Front Cell Infect Microbiol. (2018) 8:118. doi: $10.3389 /$ fcimb.2018.00118

47. Trompette A, Gollwitzer ES, Pattaroni C, Lopezmejia IC, Riva E, Pernot J, et al. Dietary fiber confers protection against flu by shaping Ly6c - patrolling monocyte hematopoiesis and CD8 + T cell metabolism. Immunity. (2018) 48:992. doi: 10.1016/j.immuni.2018.04.022

48. Steed AL, Christophi GP. The microbial metabolite desaminotyrosine protects from influenza through type I interferon. Science. (2017) 357:498502. doi: 10.1126/science.aam5336

49. Thackray LB, Handley SA, Gorman MJ, Poddar S, Bagadia P, Briseno CG, et al. Oral antibiotic treatment of mice exacerbates the disease severity of multiple flavivirus infections. Cell Rep. (2018) 22:3440. doi: 10.1016/j.celrep.2018.03.001

50. Antunes KH, Fachi JL, De Paula ROF, Silva EFD, Pral LP, Santos AAD, et al. Microbiota-derived acetate protects against respiratory syncytial virus infection through a GPR43-type 1 interferon response. Nat Commun. (2019) 10:3273. doi: 10.1038/s41467-019-11152-6

51. Murosaki S, Yamamoto Y, Ito K, Inokuchi T, Kusaka H, Ikeda H, et al. Heatkilled Lactobacillus plantarum L-137 suppresses naturally fed antigen-specific IgE production by stimulation of IL-12 production in mice. J Allergy Clin Immunol. (1998) 102:57-64. doi: 10.1016/S0091-6749(98)70055-7

52. Furusawa Y, Obata Y, Fukuda S, Endo TA, Nakato G, Takahashi D, et al. Commensal microbe-derived butyrate induces the differentiation of colonic regulatory T cells. Nature. (2013) 504:446-50. doi: 10.1038/nature12721

53. Smith PM, Howitt MR, Panikov N, Michaud M, Gallini CA, Bohloolyy M, et al. The microbial metabolites, short-chain fatty acids, regulate colonic treg cell homeostasis. Science. (2013) 341:569-73. doi: 10.1126/science.1241165

54. Lee YK, Menezes JS, Umesaki Y, Mazmanian SK. Proinflammatory Tcell responses to gut microbiota promote experimental autoimmune encephalomyelitis. Proc Natl Acad Sci USA. (2011) 108 (Suppl. 1):461522. doi: $10.1073 /$ pnas. 1000082107

55. Donaldson GP, Lee SM, Mazmanian SK. Gut biogeography of the bacterial microbiota. Nat Rev Microbiol. (2016) 14:20-32. doi: 10.1038/nrmicro3552
56. Madan JC, Koestler DC, Stanton BA, Davidson L, Moulton LA, Housman ML, et al. Serial analysis of the gut and respiratory microbiome in cystic fibrosis in infancy: interaction between intestinal and respiratory tracts and impact of nutritional exposures. MBio. (2012) 3:e00251-12. doi: 10.1128/mBio.00251-12

57. Keely S, Talley NJ, Hansbro PM. Pulmonary-intestinal crosstalk in mucosal inflammatory disease. Mucosal Immunol. (2012) 5:7-18. doi: $10.1038 / \mathrm{mi} .2011 .55$

58. Lloyd CM, Marsland BJ. Lung homeostasis: influence of age, microbes, and the immune system. Immunity. (2017) 46:54961. doi: 10.1016/j.immuni.2017.04.005

59. Wu X, Briseño CG, Durai V, Albring JC, Haldar M. Mafb lineage tracing to distinguish macrophages from other immune lineages reveals dual identity of Langerhans cells. J Exp Med. (2016) 213:2553-65. doi: 10.1084/jem.20160600

60. Wu Y, Cheng X, Jiang G, Tang H, Ming S, Tang L, et al. Altered oral and gut microbiota and its association with SARS-CoV-2 viral load in COVID-19 patients during hospitalization. NPJ Biofilms Microbiomes. (2021) 7:61. doi: 10.1038/s41522-021-00232-5

61. Kitamoto S, Nagao-Kitamoto H, Jiao Y, Gillilland MG 3rd, Hayashi A, Imai $J$, et al. The intermucosal connection between the mouth and gut in commensal pathobiont-driven colitis. Cell. (2020) 182:44762.e14. doi: 10.1016/j.cell.2020.05.048

62. Al-Asmakh M, Zadjali F. Use of germ-free animal models in microbiota-related research. J Microbiol Biotechnol. (2015) 25:1583-8. doi: 10.4014/jmb.1501.01039

63. Budden KF, Gellatly SL, Wood DLA, Cooper MA, Morrison M, Hugenholtz $\mathrm{P}$, et al. Emerging pathogenic links between microbiota and the gut-lung axis. Nat Rev Microbiol. (2017) 15:55-63. doi: 10.1038/nrmicro.2016.142

64. Date Y, Ebisawa M, Fukuda S, Shima H, Obata Y, Takahashi D, et al. NALT M cells are important for immune induction for the common mucosal immune system. Int Immunol. (2017) 29:471-8. doi: 10.1093/intimm/dxx064

65. Russell SL, Gold MJ, Hartmann M, Willing BP, Thorson L, Wlodarska M, et al. Early life antibiotic-driven changes in microbiota enhance susceptibility to allergic asthma. EMBO Rep. (2012) 13:440-7. doi: 10.1038/embor.2012.32

66. Saint-Criq V, Lugo-Villarino G, Thomas M. Dysbiosis, malnutrition and enhanced gut-lung axis contribute to age-related respiratory diseases. Ageing Res Rev. (2021) 66:101235. doi: 10.1016/j.arr.2020.101235

67. Dickson RP, Singer BH, Newstead MW, Falkowski NR, Erbdownward JR, Standiford TJ, et al. Enrichment of the lung microbiome with gut bacteria in sepsis and the acute respiratory distress syndrome. Nat Microbiol. (2016) 1:16113. doi: 10.1038/nmicrobiol.2016.113

68. Feng P, Ye Z, Kakade A, Virk AK, Li X, Liu P. A review on gut remediation of selected environmental contaminants: possible roles of probiotics and gut microbiota. Nutrients. (2018) 11:22. doi: 10.3390/nu11010022

69. Liang Y, Liang S, Zhang Y, Deng Y, He Y, Chen Y, et al. Oral administration of compound probiotics ameliorates HFD-induced gut microbe dysbiosis and chronic metabolic inflammation via the $G$ protein-coupled receptor 43 in non-alcoholic fatty liver disease rats. Probiotics Antimicrob Proteins. (2019) 11:175-85. doi: 10.1007/s12602-017-9378-3

70. Tien MT, Girardin SE, Regnault B, Le Bourhis L, Dillies MA, Coppée JY, et al. Anti-inflammatory effect of Lactobacillus casei on Shigellainfected human intestinal epithelial cells. J Immunol. (2006) 176:122837. doi: 10.4049/jimmunol.176.2.1228

71. Servin AL. Antagonistic activities of lactobacilli and bifidobacteria against microbial pathogens. FEMS Microbiol Rev. (2004) 28:405-40. doi: 10.1016/j.femsre.2004.01.003

72. Bodera P, Chcialowski A. Immunomodulatory effect of probiotic bacteria. Recent Pat Inflamm Allergy Drug Discov. (2009) 3:58-64. doi: 10.2174/187221309787158461

73. Guarino A, Lo Vecchio A, Canani RB. Probiotics as prevention and treatment for diarrhea. Curr Opin Gastroenterol. (2009) 25:18-23. doi: 10.1097/MOG.0b013e32831b4455

74. Yoda K, He F, Miyazawa K, Kawase M, Kubota A, Hiramatsu M. Orally administered heat-killed Lactobacillus gasseri TMC0356 alters respiratory immune responses and intestinal microbiota of diet-induced obese mice. $J$ Appl Microbiol. (2012) 113:155-62. doi: 10.1111/j.1365-2672.2012.05316.x

75. Ciabattini A, Olivieri R, Lazzeri E, Medaglini D. Role of the microbiota in the modulation of vaccine immune responses. Front Microbiol. (2019) 10:1305. doi: 10.3389/fmicb.2019.01305 
76. Bozkurt HS, Quigley EM. The probiotic Bifidobacterium in the management of Coronavirus: a theoretical basis. Int J Immunopathol Pharmacol. (2020) 34:2058738420961304. doi: 10.1177/2058738420961304

77. Boyle RJ, Robins-Browne RM, Tang MLK. Probiotic use in clinical practice: what are the risks? Am J Clin Nutr. (2006) 83:1256-64. doi: 10.1093/ajcn/83.6.1256

78. Tremaroli V, Bäckhed F. Functional interactions between the gut microbiota and host metabolism. Nature. (2012) 489:242-9. doi: 10.1038/nature11552

79. Pessione E. Lactic acid bacteria contribution to gut microbiota complexity: lights and shadows. Front Cell Infect Microbiol. (2012) 2:86. doi: $10.3389 /$ fcimb.2012.00086

80. Li M, van Esch B, Wagenaar GTM, Garssen J, Folkerts G, Henricks PAJ. Pro- and anti-inflammatory effects of short chain fatty acids on immune and endothelial cells. Eur J Pharmacol. (2018) 831:529. doi: 10.1016/j.ejphar.2018.05.003

81. van Zanten GC, Knudsen A, Röytiö H, Forssten S, Lawther M, Blennow A, et al. The effect of selected synbiotics on microbial composition and shortchain fatty acid production in a model system of the human colon. PLOS ONE. (2012) 7:e47212. doi: 10.1371/journal.pone.0047212

82. Matsuki T, Pédron T, Regnault B, Mulet C, Hara T, Sansonetti PJ. Epithelial cell proliferation arrest induced by lactate and acetate from Lactobacillus casei and Bifidobacterium breve. PLoS ONE. (2013) 8:e63053. doi: 10.1371/journal.pone.0063053

83. Rooks MG, Garrett WS. Gut microbiota, metabolites and host immunity. Nat Rev Immunol. (2016) 16:341-52. doi: 10.1038/nri.2016.42

84. Levy M, Thaiss CA, Elinav E. Metabolites: messengers between the microbiota and the immune system. Genes Dev. (2016) 30:1589-97. doi: 10.1101/gad.284091.116

85. Gao J, Xu K, Liu H, Liu G, Bai M, Peng C, et al. Impact of the gut microbiota on intestinal immunity mediated by tryptophan metabolism. Front Cell Infect Microbiol. (2018) 8:13. doi: 10.3389/fcimb.2018.00013

86. Singh N, Gurav A, Sivaprakasam S, Brady E, Padia R, Shi H, et al. Activation of Gpr109a, receptor for niacin and the commensal metabolite butyrate, suppresses colonic inflammation and carcinogenesis. Immunity. (2014) 40:128-39. doi: 10.1016/j.immuni.2013.12.007

87. Visconti A, Le Roy CI, Rosa F, Rossi N, Martin TC, Mohney RP, et al. Interplay between the human gut microbiome and host metabolism. Nat Commun. (2019) 10:4505. doi: 10.1038/s41467-019-12476-z
88. Morita N, Umemoto E, Fujita S, Hayashi A, Kikuta J, Kimura I, et al. GPR31dependent dendrite protrusion of intestinal CX3CR1 + cells by bacterial metabolites. Nature. (2019) 566:110-14. doi: 10.1038/s41586-019-0884-1

89. Salva S, Villena J, Alvarez S. Immunomodulatory activity of Lactobacillus rhamnosus strains isolated from goat milk: impact on intestinal and respiratory infections. Int J Food Microbiol. (2010) 141:82-9. doi: 10.1016/j.ijfoodmicro.2010.03.013

90. Hori T, Kiyoshima J, Shida K, Yasui H. Effect of intranasal administration of Lactobacillus casei Shirota on influenza virus infection of upper respiratory tract in mice. Clin Diagn Lab Immunol. (2001) 8:5937. doi: 10.1128/CDLI.8.3.593-597.2001

91. Alexander C, Swanson KS, Fahey GC Jr, Garleb KA. Perspective: physiologic importance of short-chain fatty acids from nondigestible carbohydrate fermentation. Adv Nutr. (2019) 10:576-89. doi: 10.1093/advances/nmz004

92. O’Connor KM, Lucking EF, Bastiaanssen TFS, Peterson VL, Crispie F, Cotter $\mathrm{PD}$, et al. Prebiotic administration modulates gut microbiota and faecal shortchain fatty acid concentrations but does not prevent chronic intermittent hypoxia-induced apnoea and hypertension in adult rats. EBioMed. (2020) 59:102968. doi: 10.1016/j.ebiom.2020.102968

Conflict of Interest: The authors declare that the research was conducted in the absence of any commercial or financial relationships that could be construed as a potential conflict of interest.

Publisher's Note: All claims expressed in this article are solely those of the authors and do not necessarily represent those of their affiliated organizations, or those of the publisher, the editors and the reviewers. Any product that may be evaluated in this article, or claim that may be made by its manufacturer, is not guaranteed or endorsed by the publisher.

Copyright (C) 2022 Zhao, Feng, Meng, Jin, Li and Li. This is an open-access article distributed under the terms of the Creative Commons Attribution License (CC BY). The use, distribution or reproduction in other forums is permitted, provided the original author(s) and the copyright owner(s) are credited and that the original publication in this journal is cited, in accordance with accepted academic practice. No use, distribution or reproduction is permitted which does not comply with these terms. 